\section{Quantifying the Scientific Revolution}

\author{
Benoît de Courson $^{\mathrm{a}, \square}$ and Nicolas Baumard ${ }^{\mathrm{a}, \boldsymbol{}}$ \\ ${ }^{a}$ Institut Jean Nicod, Département d'études cognitives, ENS, EHESS, PSL \\ Research University, CNRS, Paris France
}

\begin{abstract}
The Scientific Revolution is one of the most important phenomena in human history. Yet it is ill understood, partly because of a lack of quantification. Here, we leverage large datasets of individual biographies to build national estimates of scientific production during the early modern period. While aggregate levels of national production are unsurprising, per capita estimates reveal striking differences across countries, with the two richest countries of the time (England and the United Provinces) being much more scientifically productive than the rest of Europe. Overall, our study demonstrates a strong association between scientific creativity and per capita income. We also show that scientific creativity is associated with other kinds of creative activities in philosophy, literature, music and the arts, suggesting a common underlying factor. Our results also challenge long-held hypotheses regarding the role of religion, universities, demography, and the printing press, and support the idea that economic development and rising living standards are key to explaining the rise of modern science.
\end{abstract}

Scientific Revolution | Cultural Evolution | GDP per capita | Economic Development | Living Standard |

凶baumard@gmail.com, benoit.de.courson@ens.fr

The Scientific Revolution represents a turning point in the history of humanity. In the space of a few decades, it transformed the nature of knowledge and the capacities of humankind (Cohen, 2012, Mokyr, 2016, Wootton, 2015). "Without it," writes historian of science David Wootton, "there would have been no Industrial Revolution and none of the modern technologies on which we depend; human life would be drastically poorer and shorter and most of us would live lives of unremitting toil." (Wootton, 2015).

A large number of explanations have been put forward to explain the origins of the Scientific Revolution (for a review, see Cohen (1994)), from the belief in a divine legislator (Grant and Grant, 1996, Needham, 1981, Stark, 2007) to the role of medieval universities (Grant and Grant, 1996, Huff, 2017) and from political freedom (Mokyr, 2016, Needham, 1981) and to the invention of the printing press (Eisenstein, 1980, Wootton, 2015). However, testing these theories with only qualitative data is difficult. So far "there is no general agreement on what the Scientific Revolution is, why it happened - or even whether there was such a thing" (Wootton, 2015).

However, thanks to the growing size of online datasets, it is now possible to quantifying cultural production over time in science as well as in the arts (Fraiberger et al., 2018, Gergaud et al., 2017, Schich et al., 2014, Serafinelli and Tabellini, 2017, Sinatra et al., 2016). In this paper, we use the biographies of Wikipedia to quantify scientific production. In doing
Top 10 individuals

\begin{tabular}{l|c|l|c|l}
\hline Names & Languages & Country & Birth & Death \\
\hline Isaac Newton & 207 & United Kingdom & 1643 & 1727 \\
\hline Galileo Galilei & 176 & Italy & 1564 & 1642 \\
\hline Charles Darwin & 175 & United Kingdom & 1809 & 1882 \\
\hline Nicolaus Copernicus & 150 & Germany & 1473 & 1543 \\
\hline Leonhard Euler & 142 & Germany & 1707 & 1783 \\
\hline Dmitri Mendeleev & 135 & Russia & 1834 & 1907 \\
\hline Carl Friedrich Gauss & 134 & Germany & 1777 & 1855 \\
\hline Alfred Nobel & 133 & Scandinavia & 1833 & 1896 \\
\hline Johannes Kepler & 132 & Germany & 1571 & 1630 \\
\hline Gottfried Wilhelm Leibniz & 132 & Germany & 1646 & 1716 \\
\hline
\end{tabular}

Random sample of median individuals

\begin{tabular}{l|c|l|c|l}
\hline Names & Languages & Country & Birth & Death \\
\hline Marc-Auguste Pictet & 9 & Germany & 1752 & 1825 \\
\hline Wilhelm Keferstein & 9 & Germany & 1833 & 1870 \\
\hline Paolo Frisi & 9 & Italy & 1728 & 1784 \\
\hline Heinrich Schumacher & 9 & Germany & 1757 & 1830 \\
\hline Jacques Rohault & 9 & France & 1618 & 1672 \\
\hline Gabrio Piola & 9 & Italy & 1794 & 1850 \\
\hline Carl Osten-Sacken & 9 & Russia & 1828 & 1906 \\
\hline Friedrich Weber & 9 & Germany & 1781 & 1823 \\
\hline Samuel Klingenstierna & 9 & Scandinavia & 1698 & 1765 \\
\hline Nicolas Charles Seringe & 9 & France & 1776 & 1858 \\
\hline
\end{tabular}

Random sample of the bottom individuals

\begin{tabular}{l|c|l|l|l}
\hline Names & Languages & Country & Birth & Death \\
\hline Richard Pendlebury & 1 & United Kingdom & 1847 & 1902 \\
\hline Thomas Rudd & 1 & United Kingdom & 1583 & 1656 \\
\hline Walter Trevelyan & 1 & United Kingdom & 1797 & 1879 \\
\hline James Douglas Dickson & 1 & United Kingdom & 1849 & 1931 \\
\hline Alexander Yersin & 1 & Switzerland & 1825 & 1863 \\
\hline Carl Goldschmidt & 1 & Germany & 1807 & 1851 \\
\hline Antonio Filippo Ciucci & 1 & Italy & 1650 & 1710 \\
\hline Adam Anderson & 1 & United Kingdom & 1783 & 1846 \\
\hline William Campion & 1 & United Kingdom & 1820 & 1896 \\
\hline Gustav Schwartz & 1 & Austria & 1809 & 1890 \\
\hline
\end{tabular}

Table 1. Scientists ranked by the importance of their contributions to the advancement of science

so we include all individuals who are classified as scientists in Wikipedia during the early modern period: mathematicians, astronomers, geographers, physicists, biologists, naturalists, chemists, botanists, entomologists, and zoologists. The use of large datasets like this one make it possible to go beyond key figures such as Newton and Galileo and take into account the thousands of individuals who contributed to the rise of science (see Table 1). In the same way, it allows us to incorporate not only the discovery of the law of gravitation or the moons of Jupiter, but also the hundreds of mathematical theorems and astronomical discoveries that paved the way for the major breakthroughs of the Scientific Revolution.

Importantly for science, datasets like Wikipedia also convey an implicit estimate of the significance of a cultural product: the more numerous the productions of an individual, and the more important they were in the light of modern people, the bigger the biography. As such these estimates are very similar to the modern bibliometric assessment of scientific productivity, because the value of a scientific contribution is estimated by the later generations of scientists and editors of Wikipedia (see Table 1).

A further advantage of Wikipedia is that it is edited by thousands of editors, rather than by a single author or a small team of authors. For instance, the page for Galileo has been edited by 2931 different editors (excluding bots) since its creation in 2001. Even the pages of minor figures such as 


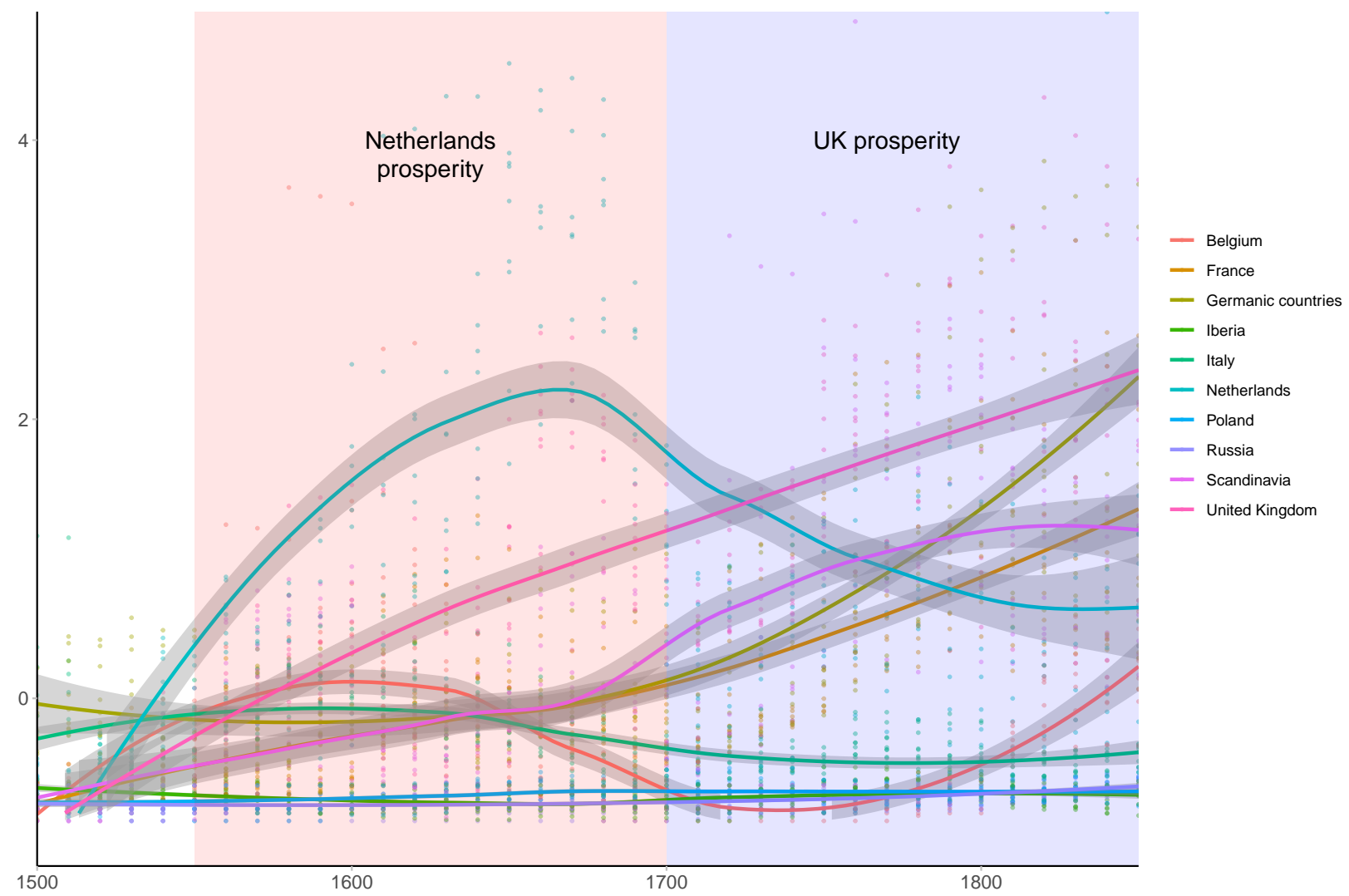

Fig. 1. National Scientific Production per capita (1500 - 1850) The economic leadership of The Netherlands (pink) and the United Kingdom (blue) in terms of per capita GDP (>1500 dollars per capita and positive growth) coincides with their leadership in per capita scientific production

Jean de Hautefeuille (1646-1724, French physicist), Thomas Johnson (1595 - 1644, English botanist) or Joachim Jungius (1597-1657, German mathematician) have been edited by more than 30 different contributors. This guarantees that the database has not been built with a particular hypothesis in mind. In fact, many methodological decisions were made by the editors of Wikipedia. For instance, for each individual, Wikipedia provides one or several "occupations" (writer, painter, theologian, etc.). This label allows us to distinguish between individuals who truly contributed to science (e.g. Ptolemy, Newton) and those who merely commented on or recorded the advances of science (e.g. Pliny the Elder, Roger Bacon, Thomas Huxley) without biasing the sample.

Combining Wikipedia entries from several different languages also allows us to limit anglocentric bias. Given the current size and influence of American and other Englishlanguage communities of historians of science compared to French-, German- or Italian-speaking communities, it could be the case that scientific contributions made by English people have been overestimated, because they are more easily accessible to English-speaking historians than the scientific contributions made in other languages. To counteract this potential bias, we used the three Wikipedias (English, German and French) whose Wikipedia communities had established lists of writers, scientists, and artists by century and nationality.

By quantifying the importance of innovators, it is possible to create a 'Scientific Domestic Product' and per capita esti- mates of scientific production for each country (see Methods below). Per capita estimates are crucial if we want to estimate levels of innovation in particular countries. For instance, we tend to consider that, in the modern period, Italy (with Galileo and Torricelli), England (with Newton and Boyle) and France (with Pascal and Descartes) were more or less equally productive scientifically (see Figure 15). But this assessment overlooks the fact that in 1650, France had 16 million people, Italy 12 million, and England only 3 million. In other words, for England to contribute as much to the Scientific Revolution, it had to be much more productive than France or Italy. As we will demonstrate, some smaller countries, such as the Netherlands or Scandinavia, were even more productive than England. However, current qualitative estimates of total national productivity fail to capture their productivity.

\section{Results}

Per Capita National Scientific Production. We calculated estimates of per capita National Scientific Production in different countries (see Fig. 1) with the Netherlands leading in the 17th century, followed by England in the 18th century. During the Scientific Revolution, these countries were much more productive than Germany, France or Italy on a per capita basis. The relative decline of Italy is visible from the early 17 th century on, starting during Galileo's lifetime. The late rise of Germany's scientific productivity is also visible, 


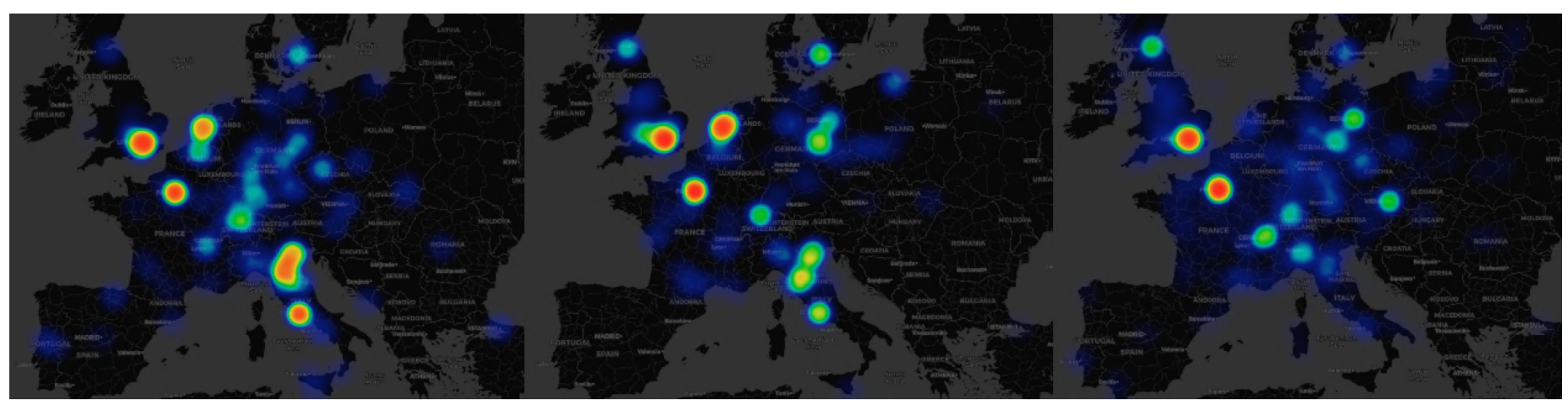

Fig. 2. Geographic distribution of scientific production (left: 16th c., center: 17th c., right: 18th c.)

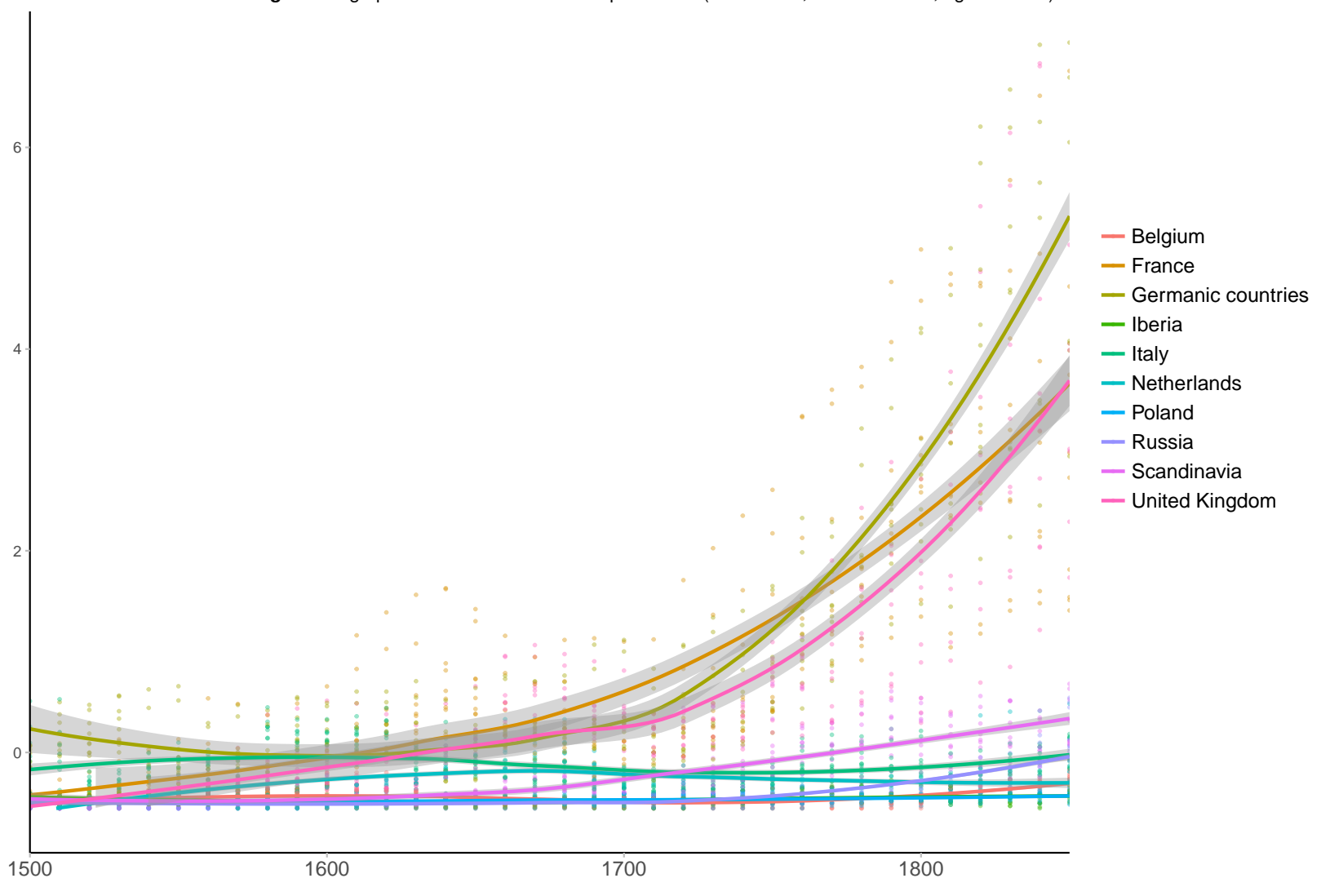

Fig. 3. National scientific production $(1500-1850)$

and foreshadows the success of German science in physics, technology and chemistry at the end of the 19th century. Finally, although Scandinavia remained a small player during the early modern period due to its small population size, it was among the most productive countries from 1700 onward. The same trend are also visible in the spatial distribution of scientists. As Figure 2 shows, scientific production was extremely concentrated in the most dynamic cities (Rome, London, Paris, Amsterdam, Florence and Venice) and shifted toward the North-West during the 17th and 18th $\mathrm{c}$.

The picture painted by these results differs considerably from the one derived from national totals (see Fig. 3). National estimates are distorted by the population size of countries. Such rankings thus do not tell us which country was the most productive at the individual level in 1700 . If we were to use them in 2019 , they would highlight the production of
China rather than Switzerland or Singapore.

It is worth nothing that the high productivity of the Netherlands is visible both across indexes (bytes, languages, quotations) and across Wikipedia languages (see Fig. 4). During their Golden Age, the Dutch were more productive than the rest of Europe regardless of the choice of indicator. This is also the case for England in the 18th century, with the exception of two of the German indicators.

This pattern could conceivably have resulted from a few outliers such as Newton and Huygens, whose fame might have biased the results in favor of England or Holland. This pattern could also have resulted from the overrepresentation of editors speaking English or Dutch, potentially leading to the creation of many biographies of minor scientists and thereby to an inflation of the productivity of England or Holland. To find out whether this was the case, we performed the 

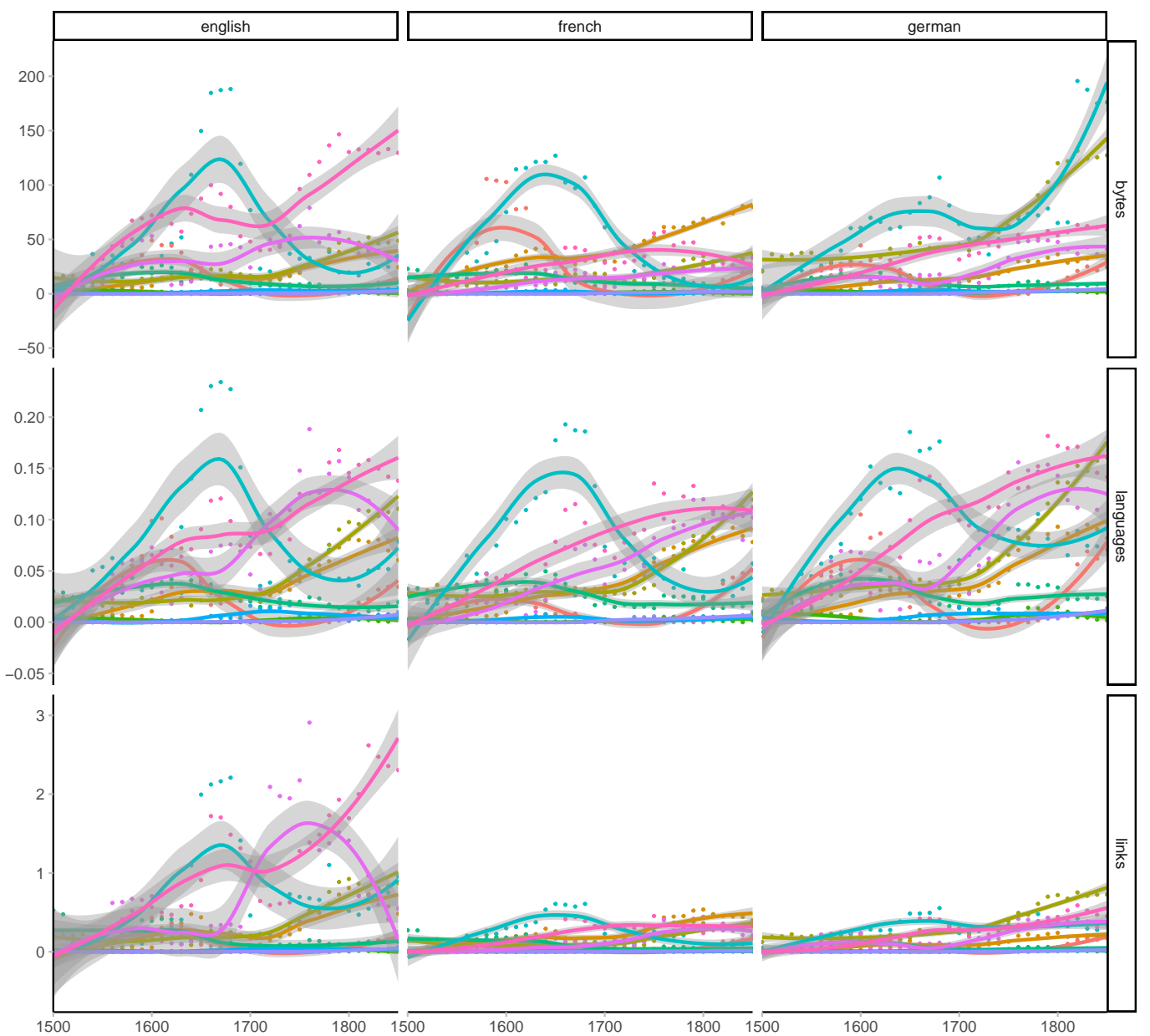

- Belgium

- France

- Germanic countries

— Iberia

- Italy

- Netherlands

- Poland

- Russia

- Scandinavia

— United Kingdom

Fig. 4. Scientific production per capita per language and per proxy (1500-1850)

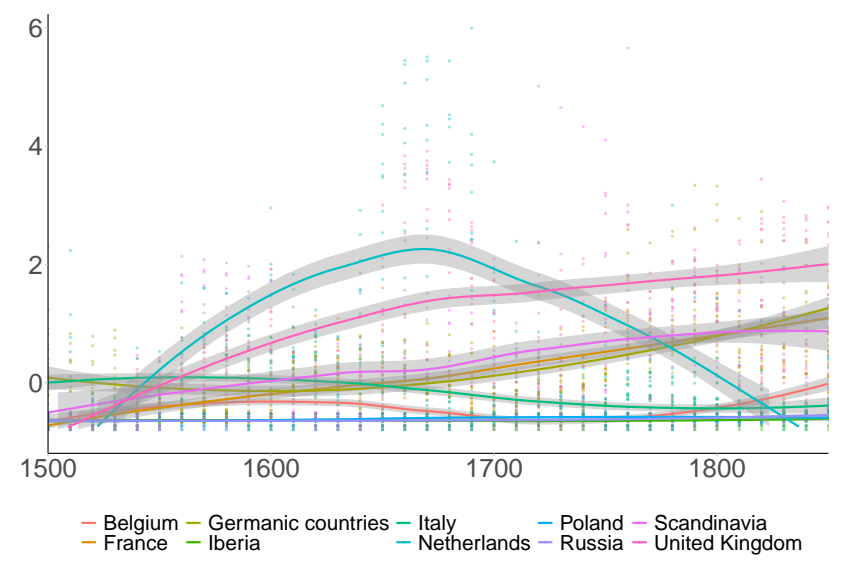

Fig. 5. Scientific Production per capita (top 10\%)

same analysis for the top $10 \%$ of scientists and for the bottom $90 \%$. We found that the pattern remained very similar in both cases (see Figs. 5 and 6).

Another potential bias is due to the fact that England and the Netherlands are smaller than Italy, France and Germany. It could thus be the case that their high productivity was due to the fact that similarly highly productive areas in France (such as Ile-de-France) or Italy (such as Tuscany) were hidden within bigger areas. To account for this possibility, we

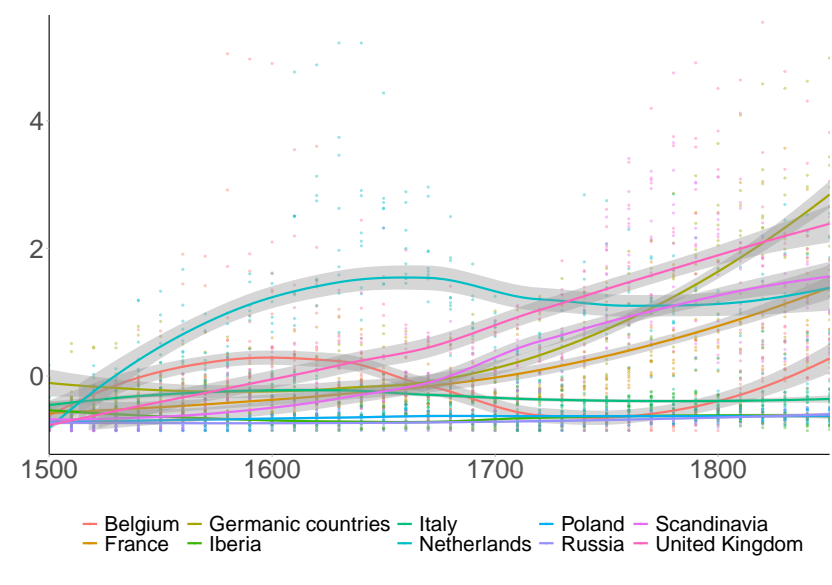

Fig. 6. Scientific Production per capita (bottom 90\%)

combined England, Scotland, Wales, Ireland, the Netherlands and Belgium into a larger unit as "Northwestern Europe", with a combined population of 12.5 million people in 1700 (compared to 22 million for France, 13 million for Germany, and 13 million for Italy). The pattern, although less spectacular, is substantially similar: Northwestern Europe comes out as the scientific leader from 1550 to 1800 (see Fig. 7).

Another potential bias is that, in Wikipedia, some very notable people such as Goethe are included in lists of scientists 


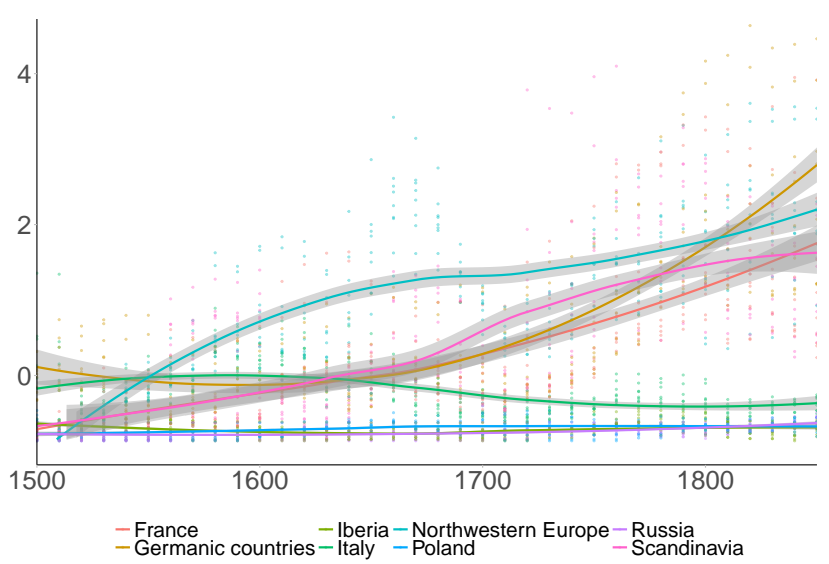

Fig. 7. Scientific Production per capita including Northwestern Europe (i.e., England, Scotland, Wales, Ireland, the Netherlands and Belgium combined)

because of their scientific contributions (although these are marginal in regard to their non-scientific contributions). It could thus be the case that the results were biased by these non-scientific celebrities. In an additional analysis, we only included individuals whose primary occupation as listed on their Wikidata item page was as a scientist (in one of the categories specified above). This did not substantially change the pattern (see Fig. 8).

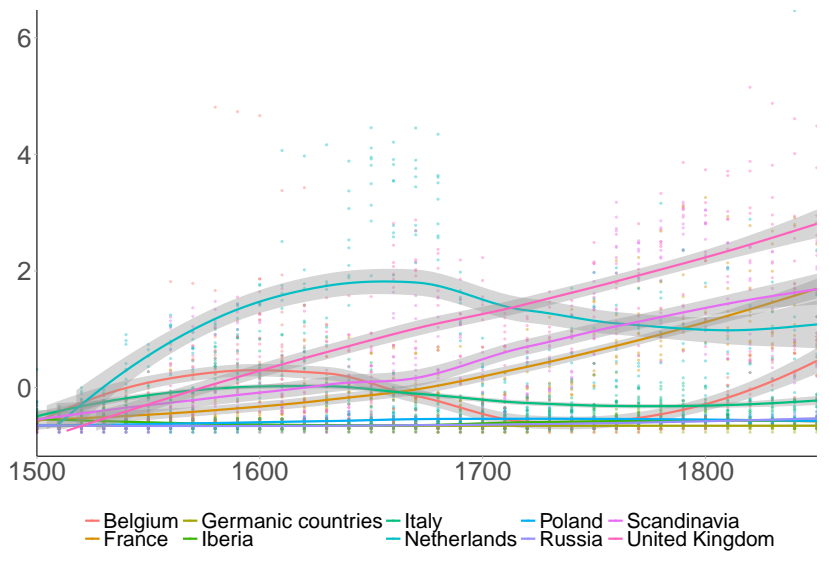

Fig. 8. Scientific Production per capita ('scientist' first occupation only)

\begin{tabular}{llllll}
\hline & Pop. & GDP pc & Univ. pc & Urbanization & Parliament \\
\hline scientists & -0.02 & $0.49^{* * *}$ & 0.07 & $0.59^{* * *}$ & $0.57^{* * *}$ \\
\hline
\end{tabular}

Table 2. Association Between Environmental variables and Scientific Creativity

Accounting for the origins of scientific productivity. Our results suggest that economic development and living standards are key to explaining scientific productivity. To further investigate this relationship, we tested the association between scientific production and two proxies for living standards: GDP per capita and urbanization rate. To investigate the link between environmental variables and scientific production, we built robust linear mixed models, whose results are displayed in Table 2. The dependent variable is the scientific production per capita, measured for each country each 50 year (to avoid any overlap between the datapoints) and for our 9 indicators (language, bytes and links). Each model has two fixed effect. First, the one mentioned in the columns, whose coefficient and associated p-value figured in the table 2 (population, GDP per capita, number of universities per capita, number of sitting days of Parliament). Second, we added the date as a covariate to (1) control for a potential historiographic bias, overstating the scientific production in the latest studied period because of the abundance of sources, and (2) to avoid a spurious correlation between affluence and scientific production, due to the fact that both affluence and scientific production tend to increase with time. As random effects, we added the country (to account for the fact that the data points associated to the same country are not fully independent), and the method used to measure scientific production (the Wikipedia language and the proxy (bytes, languages or links). To avoid any spurious result due to autoregressive components, heteroskedasticity or non-normality of residuals, we used robust regressions provided by the $\mathrm{R}$ package robustlmm. Finally, to prevent any false positive to stem from the number of tests, we applied a Bonferroni correction.

The results show a strong association between per capita scientific production and per capita GDP, book titles, and lifespan (see Table 2). Remarkably, the period of Dutch and English domination matches their period of maximum affluence during the studied period (i.e. the period during which their GDP per capita was over $\$ 2,000$ and their economic activity was growing, see Fig. 1).

We also consider alternative hypotheses. We first consider the role of religion. Protestantism has been seen as an important factor in the emergence of modern science. Following Max Weber's famous claim on the link between the Protestant work ethic and the capitalist economy, Robert K. Merton argued for a similar positive correlation between the rise of English Puritanism, as well as German Pietism, and early experimental science. He noted, for instance that seven of 10 founding members of the Royal Society were Puritans and that, in the year 1663, 62 percent of the members of the Royal Society were identified as Puritans (for more recent works on the importance of religions, see also (Harrison, 2001, LINDBERG, 1986)).

To test this idea, we created two groups of countries based on their religious affiliation at the end of the wars of religions (Peace of Westphalia, 1648), when religious affiliations get more stable. Unsurprisingly, Protestant countries appear to be more productive than Catholic countries (Fig. 9). However, this higher level of productivity appears to predate rather than follow the beginning of the Protestant Reformation by more than half a century.

To computed the date of divergence between Protestant and Catholic countries, we used the function "breakpoints" of the R package "strucchange" [https://cran.rproject.org/web/packages/strucchange/strucchange.pdf]. It follows the methodology of the Chow test: for each date, the "Chow statistic" is computed, following this formula:

$$
F=\frac{S_{c}-\left(S_{1}+S_{2}\right)}{\left(S_{1}+S_{2}\right) /(n-4)}
$$

( $S_{c}$ being the residual sum of squares for the initial model, 
$S_{1}$ and $S_{2}$ the ones for the model fitted respectively on the first and second group of observations, and $\mathrm{n}$ the total number of observations)

Intuitively, the statistic represents how much the fit is improved if, instead of fitting an OLS regression for the whole dataset, we fit one for the points anterior to this date and one for the posterior ones. Under the null hypothesis (i.e. the two regression lines have the same intercept and the same slope), $F / 2$ follows a Fisher distribution with 2 and $n-4$ degrees of freedom. It allows to compute a p-value for each possible date, quantifying how unlikely it is that the data have been generated by the same process before and after this date. The chosen breakpoint is the one that maximises the Chow statistics (and thus minimises the $\mathrm{p}$ value). It is not the only point where there is a significant structural change, but rather the point where a split maximally improves the fit. Also, it is important to understand that this analysis does not mean that there is a "burst" or a big variation at the time of the breakpoint. In fact, the position of the breakpoint can change a lot if additional years are added at the beginning and at the end of the studied period - such analysis is very sensitive to the period considered. In other words, it is not a local analysis, but a global one.

If the spread of protestantism had triggered a behavioral change, then we would likely see a significant breakpoint at this moment. Instead, the optimal breakpoint computed by the Chow test is located in 1480, that 37 years before the beginning of the Protestant Reformation. In light of these results, it can be hypothesized that the Protestant Reformation is not at the origin of the Scientific Revolution, but is rather a product of a larger cultural change that occurred in Northern Europe in the 15th and 16th centuries and that caused both the Protestant Reformation and the Scientific Revolution.

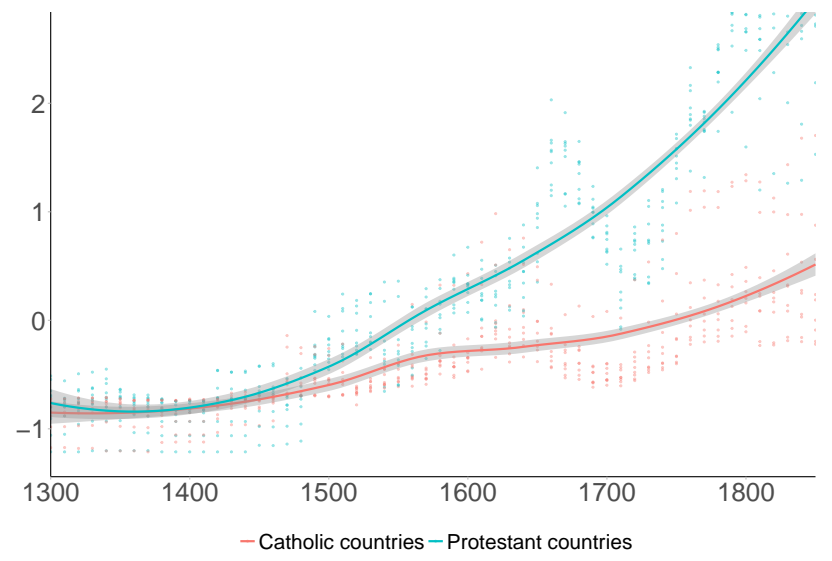

Fig. 9. Scientific production per capita for Catholic and Protestant countries

We then considered the role of printing. Printing has often been cited as a cause of the Scientific Revolution, as it allows for better communication between scientists (Eisenstein, 1980, Febvre and Martin, 1997, Wootton, 2015). Although the increase in scientific productivity coincides with the invention and diffusion of printing in Europe, there is no breakpoint associated with the invention of printing. When we consider the interval $1300-1600$ (that is the most fa- vorable to detect a breakpoint associated with the invention of printing by Gutenberg in 1440), the breakpoint that maximises the Chow statistics is 1400 , that is several decades before the invention of printing (Fig. 11).

Furthermore, the asymmetry of the growth of scientific productivity in Northern and Southern Europe (Fig. 9) suggests that its role in the Scientific Revolution was minor. Scientific productivity in the less dynamic parts of Europe (Italy, Spain, Portugal, southern France) does not seem to have been much affected by the invention of printing despite its widespread use (for instance, Venice built its first press in 1469 and had 417 printers in 1500) (see Fig. 10). This divergence between Northern and Southern Europe points toward an alternative theory in which printing is seen not as an exogenous invention but rather as an endogenous output of dynamic societies. In fact the divergence between the dynamic North and the stagnant South parallel the economic 'little divergence' observed by economic historians (De Pleijt and Van Zanden, 2016).

One important hypothesis in cultural evolution is that the probability of innovations being discovered and maintained through social learning is greater in large populations than in small ones (Collard et al., 2013, Henrich, 2004, Kremer, 1993, Shennan, 2001). Our results, however, suggest that, at least in science, population size does not play an important role in explaining per capita scientific productivity. Small societies such as England, Holland and Scotland, despite their limited population, were much more innovative than larger societies such as France, Italy or Russia (see Table 2).

We also examined the impact of universities. Medieval universities are often seen as an institutional innovation that acted as a major driver of scientific improvement (Grant and Grant, 1996, Huff, 2017). This hypothesis particularly favored when comparing European institutions of higher education and scholarship with their equivalents in Muslim, Indian and Chinese societies (Grant and Grant, 1996, Huff, 2017). Moreover, it is true that the timing of the take-off of European science matches with the creation of the major European universities (Bologna, Paris, Oxford). To test this hypothesis, we extended our study to the medieval period (500 1500). Our results show that when demography is taken into account, no significant breakpoint in the increase of scientific production can be detected during the peak period of university foundations (1100-1500) (see Fig. 12). Also, there is no association between scientific productivity and number of universities, suggesting that universities did not in fact play an important role in the Scientific Revolution (see Table 2).

This result is in line with what can be observed outside Europe. For instance, the diffusion of printed books did not drastically change China's scientific productivity during the Tang dynasty (Xu, 2017), or that of the Ottoman Empire in the 17th century (Cosggel et al., 2012). By contrast, it is worth noting that Ancient Greece achieved a level of productivity often deemed similar to that of early modern Europe despite the absence of printing.

Finally, we tested the association between scientific innovation and political freedom or inclusive institutions (Ace- 


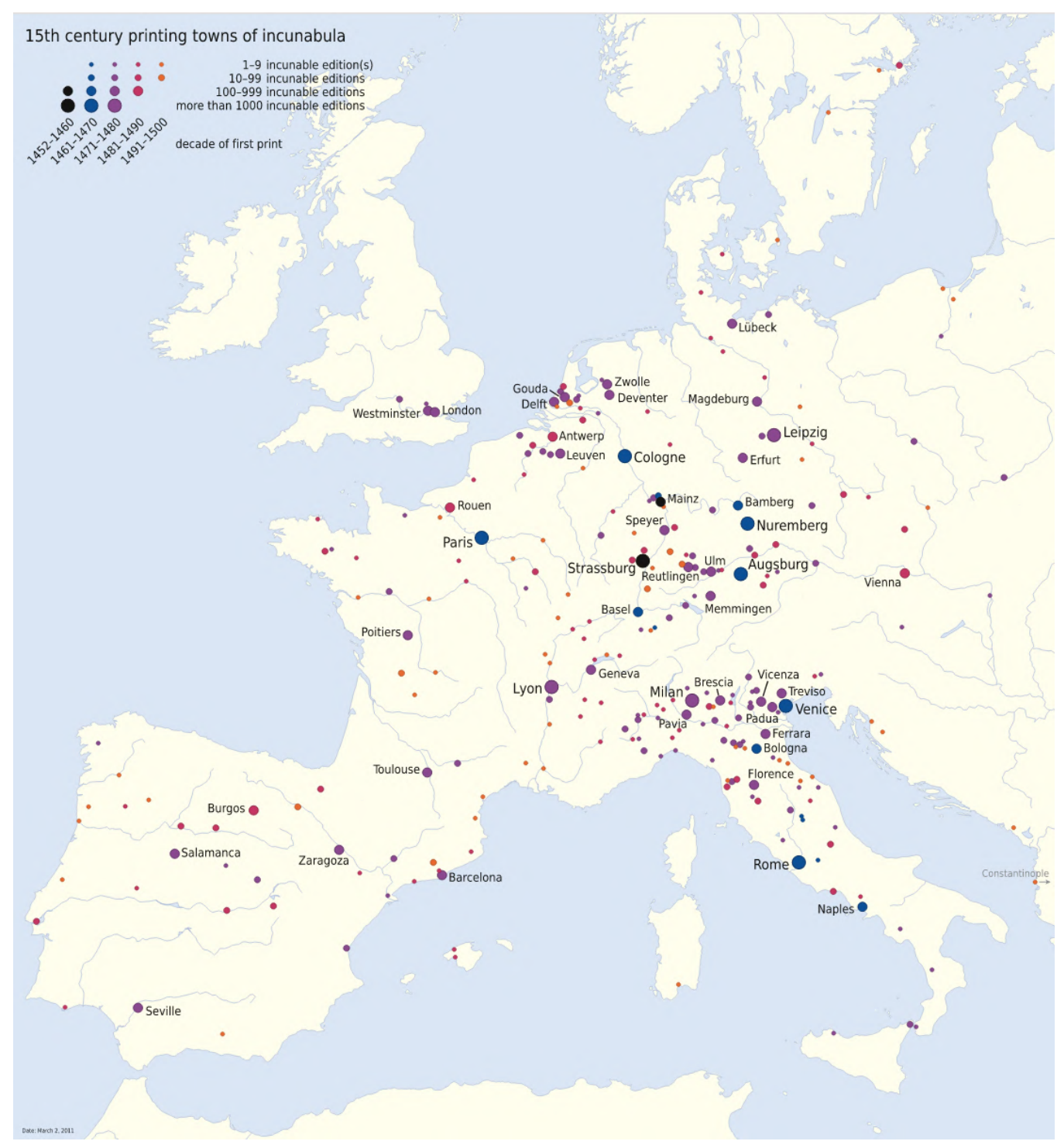

Fig. 10. Printing centres before 1500 based on the Incunabula Short Title Catalogue of the British Library (Source: NordNordWest/Wikipedia, 2019)

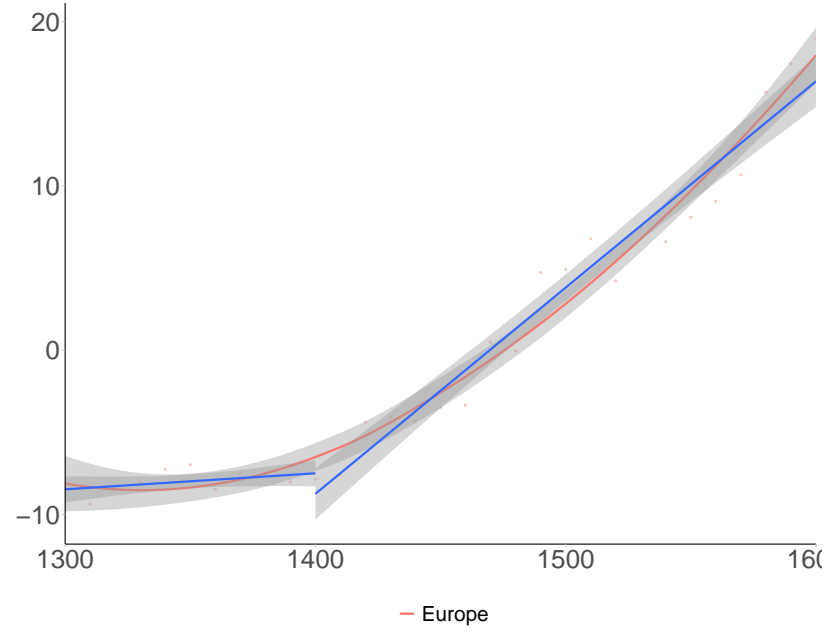

Fig. 11. Break point printing

moglu and Robinson, 2012)). Science is often described as a collaborative process, based on trust and open discussions
(Huff, 2017, Mokyr, 2016, Wootton, 2015). It stands to reason that, on this view, science should develop more easily in societies with more inclusive institutions, and where individuals enjoy greater freedom. In line with these ideas, our results show a strong association between per capita scientific production and the activity of parliaments.

\begin{tabular}{rlllll}
\hline & Pop. & GDP pc & Urbanization & Univ. pc & Parliament \\
\hline scientists & -0.02 & $0.49^{* * *}$ & $0.59^{* * *}$ & 0.07 & $0.57^{* * *}$ \\
composers & 0 & -0.05 & 0.02 & 0.09 & 0.17 \\
painters & 0.02 & $0.09^{* * *}$ & $0.1 * *$ & -0.28 & 0.08 \\
philosophers & 0.05 & 0.06 & 0.05 & 0 & 0.1 \\
sculptors & 0.02 & $0.12^{* *}$ & 0.06 & 0 & -0.07 \\
writers & 0.06 & $0.19 * * *$ & 0.12 & -0.1 & 0.04 \\
artists & 0.07 & $0.17 * * *$ & $0.35^{* * *}$ & -0.12 & $0.45^{* * *}$ \\
all & 0.07 & $0.21 * * *$ & $0.22^{*}$ & -0.2 & $0.25^{* *}$ \\
\hline
\end{tabular}

Table 3. Associations between environmental variables and cultural productions

Quantifying artistic creativity. Recent work in the behavioral sciences has shown that innovation and creativity are strongly associated with affluence, whereas harsh and unpredictable environments lead to informational conformism, the 


\begin{tabular}{rllllll}
\hline & scientists & composers & painters & philosophers & sculptors & writers \\
\hline scientists & & $0.11^{* * *}$ & $0.45^{* * *}$ & $0.51^{* * *}$ & $0.22^{* * *}$ & $0.45^{* * *}$ \\
composers & $0.17^{* * *}$ & & 0.02 & $0.15^{* * *}$ & 0.04 & $0.21^{* * *}$ \\
painters & $0.19^{* * *}$ & 0.01 & & $0.2^{* * *}$ & $0.26^{* * *}$ & $0.14^{* * *}$ \\
philosophers & $0.42^{* * *}$ & $0.14^{* * *}$ & $0.5^{* * *}$ & & $0.13^{* * *}$ & $0.35^{* * *}$ \\
sculptors & $0.22^{* * *}$ & 0.03 & $0.32^{* * *}$ & $0.19^{* * *}$ & & $0.3^{* * * *}$ \\
writers & $0.45^{* * *}$ & $0.1 * * *$ & $0.27^{* * *}$ & $0.42^{* * *}$ & $0.4^{* * *}$ & \\
\hline
\end{tabular}

Table 4. Associations between the different cultural productions

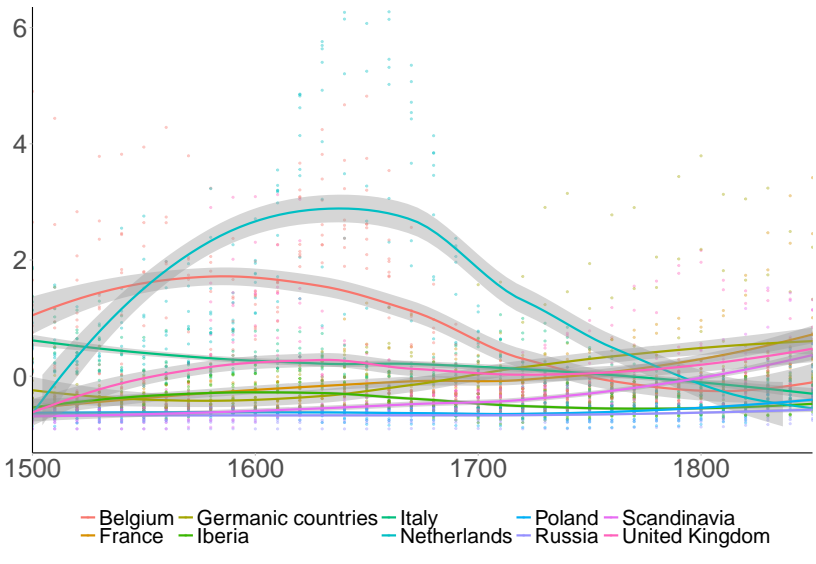

Fig. 12. Cultural production per capita (1500-1850)

tendency to defer to others' judgments (Baumard, 2018, Inglehart and Welzel, 2005, Jacquet et al., 2018, Nettle, 2018). This behavioral approach to creativity suggests that individuals in affluent environments should be more innovative in science, but also in all kinds of activities, because the tradeoffs between exploration and social learning are similar (Baumard, 2018). We thus look at other kind of creative activities, such as literature, philosophy, painting, sculpture and music, and build a general per capita "Cultural Domestic Product". In this index, scientists account for a small minority of the sample (13.2), compared to painters (40.8), writers (29) and musicians (10.1) (see Table 5). The pattern for cultural production is strikingly similar to the pattern of scientific production, with the Netherlands and then Britain leading (see Fig. 11). This suggests a common general cause behind scientific, literary, and artistic production, a "culture of growth" (Mokyr, 2016).

We also look at the correlation between cultural production and living standards using a method similar as for scientific production. Aftre correcting for multiple comparison (Bonferroni correction), the results reveal a strong association between per capita cultural production and per capita GDP, book titles, and lifespans (see Table 3). Finally, to test the prediction that all forms of cultural productions are associated to a common underlying creativity factor, we used the same robust linear mixed models to measure how much the individual cultural productions predict one another, while controlling for time, proxy and country, and correcting the p-values by Bonferroni method (see Table 4).

\section{Discussion: The Cultural Evolution of Sci- ence}

Quantitative and qualitative assessment of the Scientific Revolution. This quantitative exploration of the Scientific Revolution shows that scientific productivity was unevenly distributed in Europe, and that the most affluent countries, such as England and the Netherlands were more scientifically advanced than the rest of Europe. It is important to note that these results are in keeping with more qualitative modern assessments by historians of science (Rossi, 2001, Wootton, 2015)). They also fit with the observations of contemporaries. For instance, Voltaire, began his discussion of "great men" with the three greatest—all of them English: Bacon, Locke, and Newton (Mokyr, 2016, p. 68). Similarly, when Count Marsigli of Bologna visited the Royal Society in 1721, he was struck by the difference between Italy and England with regard to science: "[A]11 speculation unsupported by observation or experiment is utterly rejected. In England all study and teaching is based on fact" (cited in(Wootton, 2015)). As Mokyr demonstrates in The Enlightened Economy: An Economic History of Britain 1700-1850 (2012), contemporary intellectuals had a clear perception that England was ahead of its time.

In The Invention of Science, David Wootton emphasizes how advanced England was compared to the rest of Europe in 1730, the year of the publication of Voltaire's Letters Concerning the English Nation. His description of the new mentality of the English people is worth citing at length:

The message of Voltaire's book was that England had a distinctive scientific culture: what was true of an educated Englishman in 1733 would not be true of a Frenchman, an Italian, a German or even a Dutchman. Our Englishman has looked through a telescope and a microscope; he owns a pendulum clock and a stick barometer - and he knows there is a vacuum at the end of the tube. He does not know anyone (or at least not anyone educated and reasonably sophisticated) who believes in witches, werewolves, magic, alchemy or astrology; he thinks the Odyssey is fiction, not fact. He is confident that the unicorn is a mythical beast. He does not believe that the shape or colour of a plant has any significance for an understanding of its medical use. He believes that no creature large enough to be seen by the naked eye is generated spontaneously - not even a fly. He does not believe in 
the weapon salve or that murdered bodies bleed in the presence of the murderer. (...) He believes the future cannot be predicted. He knows that the heart is a pump. He has seen a steam engine at work. He believes that science is going to transform the world and that the moderns have outstripped the ancients in every possible respect. He has trouble believing in any miracles, "even the ones in the Bible". (Wootton, 2015, p. 68)

This qualitative description concords with our own results, demonstrating a very high level of scientific productivity of England at the time, a phenomenon that, far from being reducible to few outliers such as Newton or Boyle, encompasses dozens of lesser-known scientists.

The nature of the Scientific Revolution. Our study of the Scientific Revolution also reveals that, from a purely quantitative perspective, there was in fact no abrupt Scientific Revolution at all. This is visible in the Europe's overall scientific production from 600 to 1850 . Figure 13 shows a continuous acceleration of scientific production from at least the 11th century, and makes clear that there was in fact no sharp inflection point during this period.

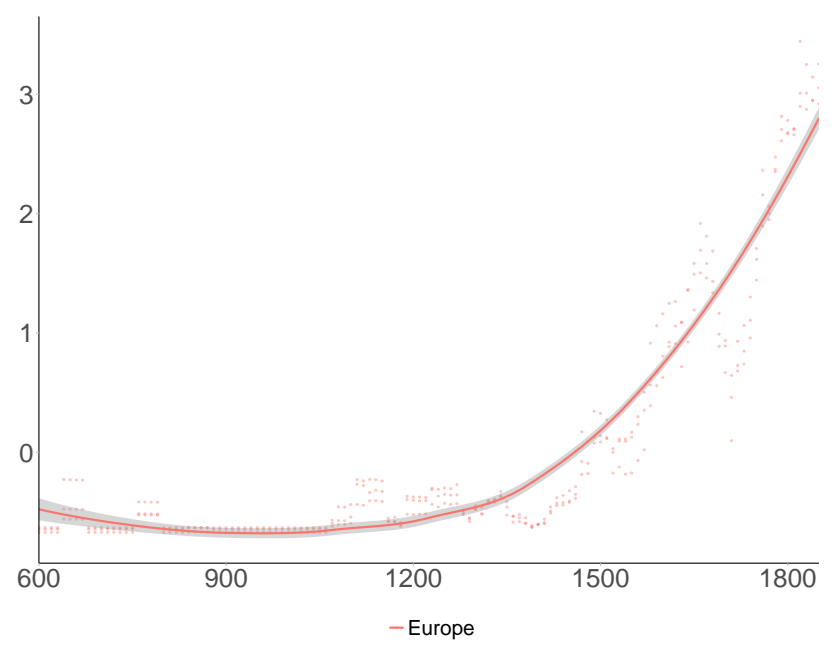

Fig. 13. European total scientific production per capita (1500-1850)

Figure 13 may thus lead us to question the very idea of the "Scientific Revolution". In the absence of quantitative measurements, we may easily be tempted to focus on a few discoveries such as the theory of heliocentrism, the theory of gravitation, or the binomial nomenclature. We may be drawn to a conceptualization of the Scientific Revolution as a shift between two radically different kinds of intellectual activities: from myth to science, from tradition to innovation, or from conformism to inventiveness. But there were much more than a few macro-discoveries during the Scientific Revolution. There were also hundreds of less important and yet crucial discoveries, from the moons of Jupiter, to the vacuum pump, to the circulation of the blood, to binomial classification. Adopting a quantitative perspective, including not only the large steps but all the smaller steps that also mattered in the advancement of science, reveals more continuity than discontinuity.

From this perspective, the acceleration of scientific production is very similar to the acceleration of economic productivity observed during the same period (see Fig. 14, and (Roser, 2014)), which leads us to question a similar, historically connected concept: the Industrial Revolution. In terms of GDP per capita over time, the Industrial Revolution hardly looks like a revolution in the sense that there is no noticeable breakpoint in per capita GDP.

One possible lesson from such quantitative findings is that while labels such as the "Scientific Revolution" can serve to raise awareness about a phenomenon (the acceleration of scientific production), they can be misleading when it comes to actually understanding it. Such labels tend to dichotomize the world (e.g., pre-scientific vs. scientific) when in reality change is continuous (i.e., varying amounts and intensities of innovation) (Baumard, 2019). In other words, 18th-century England was "more scientific" (in the sense of being scientifically more productive) than 17 th-century England, but 17thcentury England was also more scientific than 16th-century England, and so on.

This does not mean that there is nothing to be explained. The exponential rise in innovativeness still requires an explanation (André and Baumard, 2019, Enquist et al., 2008, Mesoudi, 2011). But we should not assume that the Scientific Revolution was an "event" or even a "short period." Instead it is part of a very general process of acceleration of cultural evolution, which is the phenomenon that requires an explanation. What made people more innovative? Was it new institutions, new technologies, new ideas or, as we have suggested, increasing living standards? To answer this question, we first need more data, especially on innovativeness (see below).

Note also that this conclusion is compatible with a qualitative change in people's view of science and knowledge (Wootton, 2015). The gradual increase of scientific production may have led to a tipping point at which people realized that, for instance, genuine progress (and not just the recovery of the knowledge of the past) was possible, or that there was indeed a set of practices (science) that could be isolated from the rest of culture. The possibility of relatively rapid qualitative changes in people's views of scientific production is compatible with gradual change in scientific productivity itself. The same phenomenon occured for economic growth: it took several centuries (up to the mid-19th century) for economists to realize that per capita production was increasing in England (McCloskey, 2006).

A new mentality?. Our results suggest that rising living standards and economic prosperity further the advancement of science: scientific productivity was higher in the most affluent countries, and there is a positive association between living standards and both scientific and artistic productivity. One conclusion from these results is that the Scientific Revolution is simply the output of economic development: as Aristotle noted more than two thousand years ago, prosperity gives individuals more time and resources to engage in innovative activity. 


\section{GDP per capita in England since 1270}

Adjusted for inflation and measured in British Pounds in 2013 prices

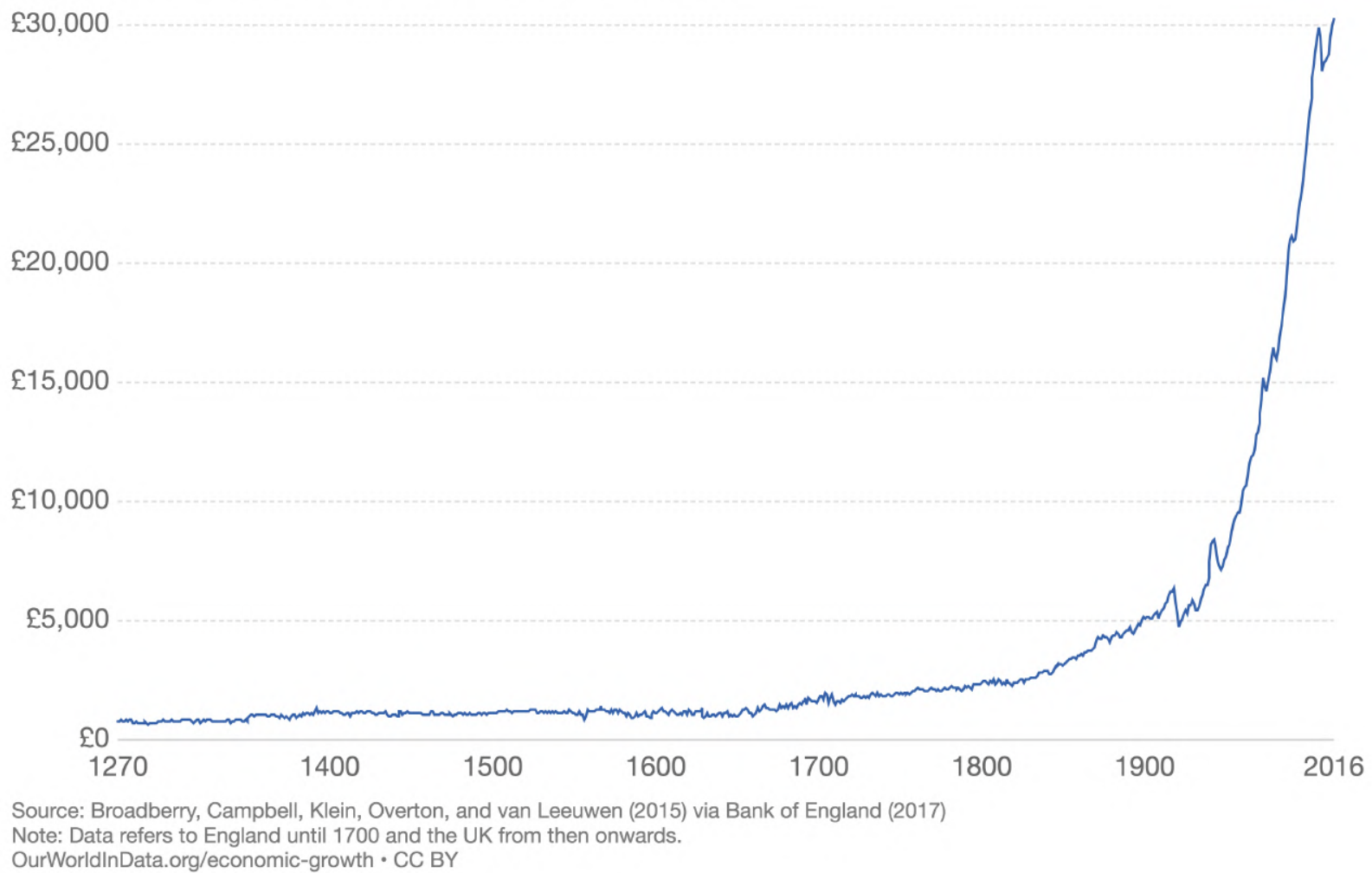

Fig. 14. GDP per capita of England (up to 1700) and the United Kingdom (1701 onward) based on Brodaberry et al., 2015 (Source: Roser, 2019 )

The history of science, however, suggests that there was more than simply more time and more resources behind scientific advances. In his account of the Scientific Revolution, David Wootton (2015) observes that, in many cases, what prevented people from advancing their knowledge was not a lack of time or money, but the inability to question authorities.

Mondino de Liuzzi (1270-1326), for example, the author of the first medieval textbook on how to perform a dissection, had plenty of hands-on experience, but he still found at the base of the human brain the rete mirabile (miraculous network) of blood vessels that Galen claimed was there, despite the fact that it isn't there at all it is only present in ungulates. Leonardo carried out dissections, but he still thought he found a channel linking the male penis to the spinal cord and so to the brain: down it he believed flowed material which became part of the ejaculate and was essential for generation. The first anatomist regularly to disagree with Galen on the basis of direct experience was Jacopo Berengario da Carpi, whose Anatomy was published in 1535 , only a few years before Vesalius's Fabric. Only in a culture where the authority of the great classical authors such as Ptolemy and Galen had be- gun to be undermined could a project like Vesalius's Fabric be undertaken. (Wootton, 2015, p.335)

Wootton makes a similar point about the 19th-century revolution in medicine. He points out that the germ theory of disease could have been discovered much earlier than the 19th century.

The primary obstacle to progress, as I have argued, was not practical (Leeuwenhoek's microscopes worked well), nor theoretical (the germ theory of putrefaction was not difficult to formulate), but psychological and cultural. It lay in doctors' sense of themselves, their awareness of their own traditions, their habit of conferring authority upon an established canon and upon established therapies. (2015, p.286)

More generally, as Wootton points out, before the 16th and 17th centuries, history was assumed to repeat itself, and tradition taken to provide a reliable guide to the future. The greatest achievements of civilization were believed to lie not in the present or the future but in the past, in ancient Greece and classical Rome. By contrast, a new optimistic attitude toward the future and the possibility of progress gradually emerged in the 16th century.

This new attitude was summed up by Louis Le Roy (or Regius, 1510-77) in 1575: 
[T]here remayne more thinges to be sought out, then are alreadie invented, and founde. And let us not be so simple, as to attribute so much unto the Auncients, that wee beleeve that they have knowen all, and said all; without leaving anything to be said, by those that should come after them.... Let us not thinke that nature hath given them all her good gifts, that she might be barren in time to come: ... How many [secrets of nature] have bin first knowen and found out in this age? I say, new lands, new seas, new formes of men, maners, lawes, and customes; new diseases, and new remedies; new waies of the Heaven, and of the Ocean, never before found out; and new starres seen? yea, and how many remaine to be (cited in (Wootton, 2015, p.118)).

A similar attitude can be found in writings by Bacon, Descartes and Galileo (Rossi, 2001, Wootton, 2015). This is reflected in the titles of the scientific books of the time: Nova de universis philosophia (Patrizi, 1591), Novo theatro de machine (Zonca, 1607), Astronomia nova (Kepler, 1609), Discursi intorno a due nuove scienze (Galileo, 1638), De mundo nostro sublunari philosophia nova (Gilbert, 1651). During the 17th century, more than a hundred books used the term novus in their title (Thorndike, 1971). As Mokyr (2016) notes, they no longer subscribed to "the Ecclesiastes view of history," which holds that long-term change is impossible, because "there is nothing new under the sun."

Not only were 17 th $\mathrm{c}$. intellectuals more optimistic, but they were also more open to creativity and innovation. As McCloskey notes, words such as "innovation" and "novelty" often used to have negative connotations before the 17 th $\mathrm{c}$.. yet, these same words started to look more positive, and emotional attachment to traditional ways of doing things progressively decreased (McCloskey, 2016, p.94).

These examples suggest that the cultural change that occurred during the period conventionally identified as the Scientific Revolution consisted at least partially in changes in mindset or mentality. One illustration of the mindset hypothesis is that, more often than not, the obstacles to the spread of the new scientific ideas are psychological, rather than technical (e.g., the need for a new instrument) or economic (e.g., the need for more education, time, books, etc.). For instance, Galileo tells the story of a professor who refused to accept that the nerves were connected to the brain rather than the heart because this was at odds with Aristotle's explicit statement-and stood his ground even when he was shown the pathways of the nerves in a dissected cadaver (Wootton, 2015). There is also the famous example of the philosopher Cremonini, who, despite being a close friend of Galileo, refused to look through his telescope for the simple reason that Aristotle did not use telescopes, and therefore they were irrelevant (Wootton, 2015).

Another argument in favor of the mindset hypothesis is that this shift in views on the progress of science predate actual scientific progress. In his famous study on the decline of magic, Keith Thomas noted that:
In many different spheres of life, the period saw the emergence of a new faith in the potentialities of human initiative. (...) The change was less a matter of positive technical progress than of an expectation of greater progress in the future. (...) It marked a break with the characteristic medieval attitude of contemplative resignation. (Thomas, 1971, p.1184)

What was striking, noted Thomas, is that this optimism in the power of technical progress could not be based on actual evidence. "It is often said that witch-beliefs are a consequence of inadequate medical technique. But in England such beliefs declined before medical therapy had made much of an advance" (Thomas, 1971, p.1211). In the same way, the popularity of the work of Francis Bacon in the 17 th century-that is, before the great wave of technical progress - attests that the English were very receptive toward optimistic ideas (Mokyr, 2016).

It is striking that similar observations can be made in the domain of technological innovation. As Howes (2016b) observes, 18th- and 19th-century innovators had an "improving mentality", seeing room for improvement everywhere.

Innovators saw room for improvement, even in wholly unfamiliar areas, and envisioned how such improvements might be brought about. It was not a particular skill or some special knowledge, but a frame of mind-a lens through which they perceived the status quo as being imperfect, and then sought to rectify those imperfections. As an analogy, consider climbing: people generally see walls or mountains as barriers, but climbers see them as objects to be scaled and clambered over. Of otherwise ordinary industries innovators said "this could be better" and then did something about it. (Howes, 2016b, p.10)

Henry Dircks, an English engineer who improved steam engines and designed optical illusions, offered this very clear characterization of this new mentality:

No work of art appears perfect to an enterprising mind. However simple its purpose, it may possibly be made lighter, stronger, more efficacious, or be done away with altogether. The man whose mind is thus constituted becomes an Inventor. (as cited in Howes, 2016a, p.8).

In the same way, innovators had limited respect for previous knowledge, and were optimistic about their own capacity to find new solutions to old problems. For instance, Henry Bessemer (steelmaking process) explained that he was very aware of his ignorance, and that he thought of it as an advantage:

My knowledge of iron metallurgy was at the time very limited... but this was in one sense an advantage to me, for I had nothing to unlearn. 
My mind was open and free to receive any new impressions, without having to struggle against the bias which a lifelong practice of routine operations cannot fail more or less to create. (as cited in Howes, 2016a, p.10).

Technological innovators were optimistic and nonconformist: they had a new mentality.

Explaining the new attitudes toward innovation and exploration. What might explain the decline of conformism and the rise of optimism? An important factor may be the unprecedented living standards experienced by English people (and more generally by Europeans) from the 17th century onward (Allen et al., 2011, Cummins, 2014, Fouquet and Broadberry, 2015, Morris, 2013). Affluence has predictable effects on human psychology (for a recent review, see Pepper and Nettle (2017), and can alter the dynamics of cultural evolution (Baumard and Chevallier, 2015, Baumard et al., 2015). In particular, recent research inspired by lifehistory theory have shown that in a harsh environment, when the levels of available resources are low and unpredictable, individuals tend to be more short term-oriented, more risk averse, and more conservative. By contrast, in a resourcerich environment, individuals are future-oriented, risk-prone and open-minded (Baumard, 2018).

This result fits well with recent finding suggesting that innovation and creativity are strongly associated with affluence and that, on the contrary, harsh and unpredictable environments lead to informational conformism, the tendency to defer to others' judgments (Baumard, 2018, Inglehart, 2018, Jacquet et al., 2018, Nettle, 2018). The basic rationale for this association between environmental harshness and informational conformism is that copying others is cheaper than exploring by oneself, a rationale that has been widely used to study the trade-off between exploration and exploitation in animal foraging (Boyd and Richerson, 1988, Laland and Williams, 1998, Rieucau and Giraldeau, 2011). When resources are abundant, individuals should be interested in cognitive investment and cognitive exploration, and thus be curious, independent and open-minded. On the contrary, when resources are low, individuals should not waste their scarce resources in exploring their environment, but should be conservative and conformist (Jacquet et al., 2018, Nettle, 2018).

The rising living standards experienced by Europeans may thus have changed individuals' psychology, from a pessimistic, conformist and conservative outlook toward a more optimistic, non-conformist and progressive one. As a result, Europeans would have started being more confident in their capacity to change the world, to propose new theories and to test them. In turn, this optimism may have made the experimental method and natural philosophy more appealing (despite the fact that, in the 17th century, there was as yet no evidence that experiments and science could really improve people's situation).

Limitations of this study. Our study has revealed a strong association between affluence and scientific productivity.
However, this does not demonstrate a causal link between the two phenomena. For instance, changes in both prosperity and creative productivity could have been caused by another, hidden change in history. One candidate is institutional change. Thus, it could be that inclusive institutions caused a rise in both scientific productivity and affluence (Acemoglu and Robinson, 2012, North, 1990) which would explain our finding that scientific productivity, affluence, and inclusive institutions are highly correlated. One problem with this explanation is that it does not explain why some countries were lucky enough to get inclusive institutions while others only got inefficient institutions. In fact, a growing body of works both in political science (Abramson and Boix, 2014, Boix and Stokes, 2003) and in the behavioral sciences (Petersen and Aarøe, 2015, Safra et al., 2017) suggests that better life conditions are associated with higher level of interpersonal trust and higher support for inclusive institutions. In other words, institutional development, political freedom and inclusiveness are endogenous, not exogeneous, and they accompany economic development (Boix and Stokes, 2003). In any case, future work should use causal or quasi-causal methods and find variables in datasets that are assigned in a way that is as good as random, as in the case, for example, of the distance from the coast in the study of the impact of the Atlantic slave trade (Nunn and Qian, 2011), or soil composition when studying the impact of the introduction of the heavy plow (Andersen et al., 2016).

Another limitation of this study is that it is focused on early modern Europe, whereas scientific production has been notable levels of other societies and earlier periods: in particular in Ancient Greece, in the Arab and Persian worlds, and in South and East Asia. Recent works in economic history suggests that these periods in these places were also characterized by increasing living standards (Morris, 2013, Ober, 2015). Future work should aim to test whether the association between affluence and scientific production holds for non-European societies, and whether increased prosperity could explain the rise of science in 4th-century Athens or 10th-century Baghdad.

\section{Methods}

Scientific and Artistic Production. To collect the datasets, we used a top-down approach based on Wikipedia categories (Gergaud et al., 2017). First, we manually identified all the relevant Wikipedia categories (for instance, "18th century Italian mathematicians").

We only included individuals working in the "hard sciences": mathematicians, physicists, astronomers, chemists, biologists, botanists, and zoologists (the first three categories account for more $90 \%$ of the sample). The rationale for this choice is that these domains correspond to the core domains of the 17th century Scientific Revolution. It also corresponds to what economists call "useful knowledge," the kind of knowledge involved in the manipulation of the material world, and the main source of growth during the Industrial Revolution (Jacob, 1997; Mokyr, 2016). In any case, the number of social scientists in Wikipedia before 1850 is too 
limited for a quantitative study. We also excluded physicians, because their biographies are mostly concerned not with scientific advances, but with their social role at the time. Moreover, given medical doctors' poor record at increasing medical knowledge before the late 19th century, they arguably do not represent a good proxy for innovation (Wootton, 2007).

We also wanted to measure cultural creativity in general. We thus included all occupations that involve an important component of innovation and creativity: writers, philosophers, painters, musicians and sculptors. By contrast, we excluded rulers, military personnel, lawyers, religious leaders, and physicians because these occupations arguably do not involve the same level of creativity. Some extra creative occupations could have been included, but were excluded due to the small number of individuals in each category: engineers, geographers, explorers, cartographers, or architects. In total, 22,943 individuals were included in the dataset (see Table 2).

\begin{tabular}{c|c}
\hline Discipline & Number of pages \\
\hline scientists & 3017 \\
\hline composers & 2311 \\
\hline painters & 9366 \\
\hline writers & 6631 \\
\hline philosophers & 441 \\
\hline sculptors & 1177 \\
\hline
\end{tabular}

Table 5. Number of individuals per occupation

We included in our sample all modern countries for which there were lists by nationality in science for the 19th century or before. Our final list includes the following countries: Belgium, UK, France, Germanic countries (Germany, Austria, Switzerland), Italy, the Netherlands, Iberia (Spain and Portugal), Poland, Russia and Scandinavia (see Fig. 15). We created two aggregated countries (Germanic countries and Iberia) because some environmental variables were only available at this level (see below, urbanization).

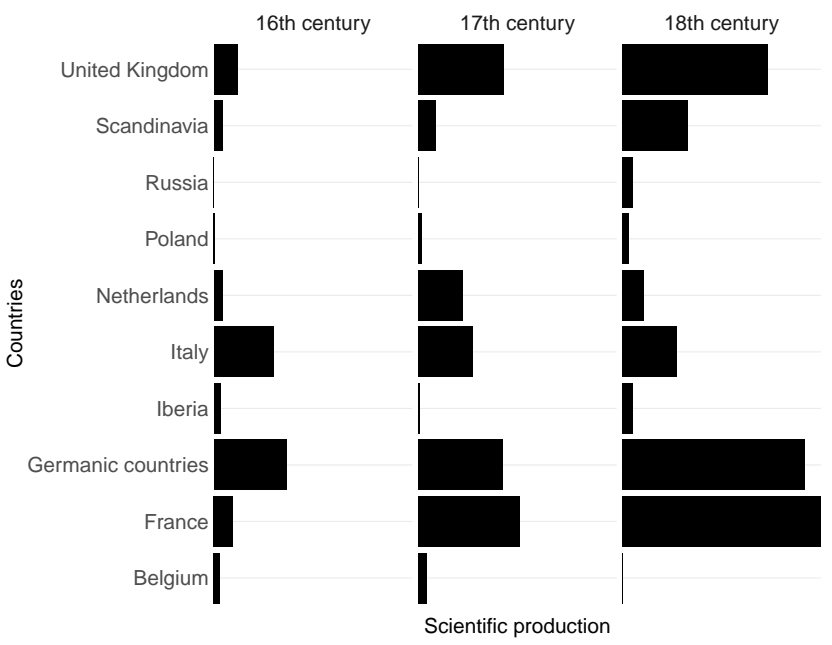

Fig. 15. Number of individuals per country

Where country of citizenship (around 30\% of the pages) was not specified on the individual's Wikidata item page, we inferred it using two methods. First, when possible, we referred to the Wikipedia category in which we had found the page (e.g., someone belonging to the category of "Italian mathematicians" was considered Italian). Second, when this was not possible, a script looked at the first words on the page, more precisely those following the pattern "[Name] ([dates]) was a...". Therefore, a page beginning with "Galileo Galilei (15 February 1564 - 8 January 1642) was an Italian astronomer" meant that Galileo would be classified as Italian. Finally, for the most incomplete datasets (Renaissance scientists, Renaissance philosophers), we added country information manually.

We collected three proxies for the importance of an individual's contribution to the advancement of science (Gergaud et al., 2017):

1. Length: The number of bytes in the Wikipedia page (from "Page Information") 2. Languages: The number of languages in which there was a page for the individual (from Wikidata) 3. Quotation: The number of Wikipedia pages containing a link toward this page (from the corresponding Wikidata item page).

None of these indexes is perfect, and they all have their biases, so we calculated z-scores for each of them, and combined the three to create a more general index of Individual Scientific Productivity (for scientists) or Artistic Indivividual Productivity (for artists)(see Fig. 4).

To avoid a potential language bias leading to an overestimation of British production, we ran this study on the three largest Wikipedias: English, French and German. Contrary to our expectations, the datasets from the French and German Wikipedias were not always smaller than those from English Wikipedia (for instance, the German-language dataset of scientists is much larger than the English-language dataset, while the opposite is true for painters). Note also that previous work on notable individuals in Wikipedia has demonstrated that while a small portion of lesser-known individuals are present in non-English pages but absent in English pages, this is not the case for the most notable individuals (Gergaud et al., 2017).

Next, for a given year (here noted y), we computed the Total Scientific Product. Assuming an average peak productivity at 35, we used the following formula: National Scientific Product is the sum of the Individual Scientific Productivity of all individuals who reached the age of 35 between the year $y$ -25 and the year $y+25$ in a given country.

To get per capita estimates, we divided the National Scientific Product by the estimate population in year y (estimates are taken from the Atlas of World Population (McEvedy, Jones \& others, 1978). This provided demographic estimates for every century, or every 50 years. We thus performed a linear extrapolation to derive population figures at ten-year intervals for each country.

Because we were interested in the dynamics of the Scientific Revolution, which is usually dated around 1650, we choose 1500 as the starting date of our study and 1850 as the ending date.

Environmental variables. In order to study the ecological determinants of scientific production, we used three mea- 
sures of standard of living: GDP per capita (Broadberry et al., 2017) and urbanization ratio (Bosker et al., 2013), as well as a crude estimate of lifespan (Cummins, 2014).

To test the importance of universities, we used the number of universities retrieved from Wikipedia's "List of medieval universities" and "List of oldest universities in continuous operation".

To test the importance of inclusive institutions, we used two measures: the number of autonomous cities per country (Stasavage, 2014) and the the number of calendar years per century in which for the various areas a parliament (or estates-general, cortes, corts, diet, sejm, riksdag, Generallandtag, or Reichstag) assembled for official sessions during shorter or longer periods in a year (Van Zanden et al., 2012). This measure can vary from zero, when no parliament was convened (or none existed), to 100, when a meeting took place in every year of the century.

To test the effect of Protestantism, we created two groups of countries based on their religious affiliation after the Wars of Religion and the Treaty of Westphalia, when the borders of each religion were more and less settled. Protestant countries include England, Scotland, Germany, the Netherlands, Switzerland and Scandinavia. Catholic countries include France, Italy, Portugal, Spain and Belgium.

To test the effect of the printing press, we compared scientific productivity before and after Gutenberg's invention of the printing press around 1440 .

We took these environmental variables as predictors, plotted linear regressions of country-level cultural production against each variable, and computed correlation coefficients for production (taken as the mean of the z-scores for the 9 estimates).

\section{Acknowledgements}

We thank Lou Safra and Mauricio Martins for their help in analysing the data and Paul Reeve for his careful correction of the draft.

\section{References}

Abramson, S. and C. Boix, 2014. The Roots of the Industrial Revolution: Political Institutions or (Socially Embedded) Know-How? Unpublished typescript, Princeton University.

Acemoglu, D. and J. Robinson, 2012. Why nations fail: The origins of power, prosperity, and poverty. Crown Business.

Allen, R. C., J.-P. Bassino, D. Ma, C. Moll-Murata, and J. L. Van Zanden, 2011. Wages, prices, and living standards in China, 1738-1925: in comparison with Europe, Japan, and India. The Economic History Review 64:8-38.

Andersen, T. B., P. S. Jensen, and C. V. Skovsgaard, 2016. The heavy plow and the agricultural revolution in Medieval Europe. Journal of Development Economics 118:133-149.

André, J.-B. and N. Baumard, 2019. Cultural evolution by capital accumulation. bioRxiv P. 707620

Baumard, N., 2018. Psychological origins of the industrial revolution. Behavioral and Brain Sciences Pp. 1-47.

, 2019. Psychological Origins of the Industrial Revolution: More Work is Needed! Behavioral and Brain Sciences .

Baumard, N. and C. Chevallier, 2015. The nature and dynamics of world religions: a life-history approach. in Proc. R. Soc. B, vol. 282, P. 20151593. The Royal Society.

Baumard, N., A. Hyafil, I. Morris, and P. Boyer, 2015. Increased affluence explains the emergence of ascetic wisdoms and moralizing religions. Current Biology 25:10-15.

Boix, C. and S. C. Stokes, 2003. Endogenous democratization. World politics 55:517-549.

Bosker, M., E. Buringh, and J. L. van Zanden, 2013. From Baghdad to London: Unraveling Urban Development in Europe, the Middle East, and North Africa, 800-1800. Review of Economics and Statistics 95:1418-1437.

Boyd, R. and P. J. Richerson, 1988. Culture and the evolutionary process. University of Chicago press.

Broadberry, S. N., H. Guan, and D. D. Li, 2017. China, Europe and the Great Divergence: A Study in Historical National Accounting, 980-1850
Cohen, H. F., 1994. The scientific revolution: a historiographical inquiry. University of Chicago Press.

, 2012. How modern science came into the world: Four civilizations, one 17th-century breakthrough. Amsterdam University Press.

Collard, M., A. Ruttle, B. Buchanan, and M. J. O'Brien, 2013. Population size and cultural evolution in nonindustrial food-producing societies. PloS one 8:e72628.

Coşgel, M. M., T. J. Miceli, and J. Rubin, 2012. The political economy of mass printing: Legitimacy and technological change in the Ottoman Empire. Journal of Comparative Economics 40:357-371.

Cummins, N., 2014. Longevity and the Rise of the West: Lifespans of the European Elite, 8001800. Browser Download This Paper.

De Pleijt, A. M. and J. L. Van Zanden, 2016. Accounting for the "Little Divergence": What drove economic growth in pre-industrial Europe, 1300-1800? European Review of Economic History 20:387-409.

Eisenstein, E. L., 1980. The printing press as an agent of change, vol. 1. Cambridge University Press.

Enquist, M., S. Ghirlanda, A. Jarrick, and C.-A. Wachtmeister, 2008. Why does human culture increase exponentially? Theoretical population biology 74:46-55.

Febvre, L. and H.-J. Martin, 1997. The coming of the book: the impact of printing 1450-1800, vol. 10. Verso.

Fouquet, R. and S. Broadberry, 2015. Seven centuries of European economic growth and decline. The Journal of Economic Perspectives 29:227-244.

Fraiberger, S. P., R. Sinatra, M. Resch, C. Riedl, and A.-L. Barabási, 2018. Quantifying reputation and success in art. Science 362:825-829.

Gergaud, O., M. Laouenan, and E. Wasmer, 2017. A Brief History of Human Time. Exploring a database of" notable people"

Grant, E. and E. E. Grant, 1996. The foundations of modern science in the Middle Ages: their religious, institutional and intellectual contexts. Cambridge University Press.

Harrison, P., 2001. The Bible, Protestantism, and the Rise of Natural Science. Cambridge University Press. Google-Books-ID: eBLst8a8uYYC.

Henrich, J., 2004. Demography and cultural evolution: how adaptive cultural processes can produce maladaptive losses-the Tasmanian case. American Antiquity 69:197-214.

Howes, A., 2016a. The Improving Mentality: Innovation during the British Industrial Revolution, 1651-1851.

, 2016b. The Relevance of Skills to Innovation during the British Industrial Revolution, $1651-1851$

Huff, T. E., 2017. The rise of early modern science: Islam, China, and the West. Cambridge University Press.

Inglehart, R., 2018. Cultural Evolution: People's Motivations are Changing, and Reshaping the World. Cambridge University Press.

Inglehart, R. and C. Welzel, 2005. Modernization, cultural change, and democracy: The human development sequence. Cambridge University Press.

Jacquet, P. O., V. Wyart, A. Desantis, Y.-F. Hsu, L. Granjon, C. Sergent, and F. Waszak, 2018. Human susceptibility to social influence and its neural correlates are related to perceived vulnerability to extrinsic morbidity risks. Scientific reports 8:13347.

Kremer, M., 1993. Population growth and technological change: One million BC to 1990. The Quarterly Journal of Economics 108:681-716.

Laland, K. N. and K. Williams, 1998. Social transmission of maladaptive information in the guppy. Behavioral Ecology 9:493-499.

LINDBERG, e., 1986. God and Nature: Historical Essays on the Encounter Between Christianity and Science. University of California Press. Google-Books-ID: beRh2rLUsMIC.

McCloskey, D. N., 2006. Bourgeois Virtue. Wiley Online Library.

, 2016. Bourgeois equality: How ideas, not capital or institutions, enriched the world. University of Chicago Press.

Mesoudi, A., 2011. Variable cultural acquisition costs constrain cumulative cultural evolution. PloS one 6:e18239.

Mokyr, J., 2016. A Culture of Growth: The Origins of the Modern Economy. Princeton University Press.

Morris, I., 2013. The measure of civilization: how social development decides the fate of nations. Princeton University Press.

Needham, J., 1981. Science in traditional China: a comparative perspective. Chinese University Press.

Nettle, D., 2018. State-dependent cognition and its relevance to cultural evolution. Behavioural processes

North, D. C., 1990. Institutions, institutional change and economic performance. Cambridge university press.

Nunn, N. and N. Qian, 2011. The potato's contribution to population and urbanization: evidence from a historical experiment. The Quarterly Journal of Economics 126:593-650.

Ober, J., 2015. The rise and fall of classical Greece. Princeton University Press.

Pepper, G. V. and D. Nettle, 2017. The behavioural constellation of deprivation: causes and consequences. The Behavioral and brain sciences P. 1.

Petersen, M. B. and L. Aarøe, 2015. Birth Weight and Social Trust in Adulthood Evidence for Early Calibration of Social Cognition. Psychological science 26:1681-1692.

Rieucau, G. and L.-A. Giraldeau, 2011. Exploring the costs and benefits of social information use: an appraisal of current experimental evidence. Philosophical Transactions of the Royal Society of London B: Biological Sciences 366:949-957.

Roser, M., 2014. GDP growth over the very long run. OurWorldlnData. org

Rossi, P., 2001. The birth of modern science. Wiley-Blackwell.

Safra, L., Y. Algan, T. Tecu, J. Grèzes, N. Baumard, and C. Chevallier, 2017. Childhood harshness predicts long-lasting leader preferences. Evolution and Human Behavior .

Schich, M., C. Song, Y.-Y. Ahn, A. Mirsky, M. Martino, A.-L. Barabási, and D. Helbing, 2014. A network framework of cultural history. science 345:558-562.

Serafinelli, M. and G. Tabellini, 2017. Creativity over time and space

Shennan, S., 2001. Demography and cultural innovation: a model and its implications for the emergence of modern human culture. Cambridge archaeological journal 11:5-16.

Sinatra, R., D. Wang, P. Deville, C. Song, and A.-L. Barabási, 2016. Quantifying the evolution of 
individual scientific impact. Science 354:aaf5239.

Stark, R., 2007. The victory of reason: How Christianity led to freedom, capitalism, and Western success. Random House.

Stasavage, D., 2014. Was Weber right? The role of urban autonomy in Europe's rise. American Political Science Review 108:337-354.

Thomas, K., 1971. Religion and the decline of magic: studies in popular beliefs in sixteenth and seventeenth-century England. Penguin UK.

Van Zanden, J. L., E. Buringh, and M. Bosker, 2012. The rise and decline of European parliaments, 1188-1789. The Economic History Review 65:835-861.

Wootton, D., 2007. Bad medicine: doctors doing harm since Hippocrates. Oxford University Press.

2015. The invention of science: A new history of the scientific revolution. Penguin UK.

$\mathrm{Xu}, \mathrm{T} .$, 2017. The Production and Circulation of Manuscripts and Printed Books in China Compared to Europe, ca. 581-1840. Europe 581. 